\title{
Who is entitled to the title of "doctor"?
}

$\mathrm{T}$ wo letters, one period, so much fuss. Then again, this short combination of letters and punctuation is rather coveted. It projects expertise and draws respect. It indicates status, accomplishment, years of study. It earns patients' trust. It makes parents proud. So perhaps it should be no surprise that more health care professionals want to see the honorific "Dr." before their names.

But who should be allowed to call themselves a doctor? That remains a matter of debate, especially in health care. Some non-physicians say they have achieved doctoral-level degrees and deserve the title. Others wonder if this is merely careerism that will confuse, not help, patients in clinical settings.

'I'm very comfortable with doctors of audiology, doctors of nutrition, doctors of pharmacy. I often see someone say, 'I'm Dr. so-and-so, and I'm a pharmacist.' That's not that unusual," said Dr. Wanda Filer, president of the American Academy of Family Physicians. "The big issue is to make sure the patient knows who they are talking to."

This issue recently resurfaced in Canada, after an Ontario audiologist named Brenda Berge launched a freedom of expression challenge before the Ontario Divisional Court for the right to be called a doctor. Though Ontario law allows various health care professionals without medical degrees to use the "Dr." honorific — dentists, naturopaths and chiropractors among them - the privilege is not extended to audiologists.

Berge, who has a doctoral-level degree, had previously been using the title, until the College of Audiologists and Speech Language Pathologists of Ontario found her guilty of misconduct. The college suspended Berge for three months. She also had to take a course in professional ethics and pay the college nearly $\$ 100000$ in costs.

According to Filer, however, bringing more expertise into patient care from other medical disciplines is a good thing. And if those experts have the credentials and want to call themselves doctors, so be it. As long as there is no intent to mislead patients,

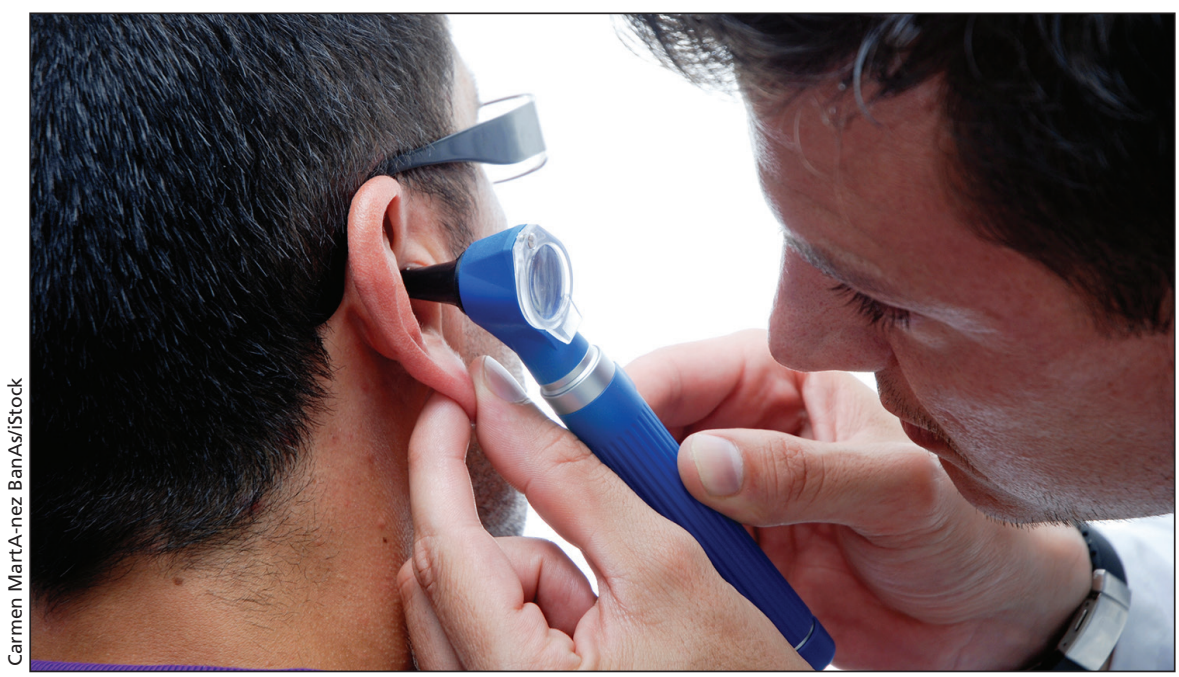

Would allowing more health care professionals, such as audiologists, to use the title "doctor" benefit patients or only careers?

and all professionals are aware of their abilities and boundaries, why wouldn't physicians respect the wishes of colleagues who want to be called doctors?

"I think we need to avoid, as professionals, demeaning each other. We need to think collectively about what is best for patients," said Filer. "Quite frankly, as I read about the case and the credentials of that audiologist, in my mind, she's a doctor of audiology, flat out. From the training she has had, I'd be very happy to have her see my patients.'

One of Filers' predecessors didn't appear to hold the same opinion. In a 2011 article in the New York Times, Dr. Roland Goertz, who was then the board chair of the American Academy of Family Physicians, said that physicians were worried about losing control over the title of "doctor" because it could lead to loss of control over the medical profession itself. "There is real concern that the use of 'doctor' will not be clear to patients," he told the newspaper.

In 2009, the College of Physicians and Surgeons of Ontario provided input to the Minister of Health and Long-Term Care about the use of the title "doctor." One of the main concerns was that the lack of consistent requirements for professionals permitted to be called "doctor" would be confusing to the public. "Within a health care setting, the public typically associ- ates the title 'doctor' with those who provide medical treatment and advice," the letter states. "Identifying non-physician doctorates by the title 'doctor' may lead to misconceptions from the public that such individuals, when working in a health care setting, are able to offer medical treatment and advice.'

According to Kathryn Clarke, senior communications coordinator for the college, restricted titles are an essential public-protection component in regulating health professions. They help patients identify various health care professions, distinguish the qualified from the unqualified and differentiate practitioners who are regulated from those who aren't.

"A significant factor to be considered before a health-care professional is permitted to use the designation doctor is, at minimum, consistent and rigorous educational, training and accreditation requirements to ensure consistency amongst health professionals permitted to use this restricted title while providing health care to patients," Clarke said in an email. "In this way patients will know that the health care professional with whom they are dealing is regulated by a college, and is therefore duly qualified and subject to disciplinary processes for incompetent, impaired or unethical practice." - Roger Collier, CMAJ 